\title{
Low-Hysteresis Shape Memory Alloy Scale-Up: DSC, XRD and Microstructure Analysis on Heat-Treated Vacuum Induction Melted Ni-Ti-Cu-Pd Alloys
}

\author{
Jannis Nicolas Lemke *, Federico Gallino, Matteo Cresci, Stefano Zilio and Alberto Coda
}

\section{check for} updates

Citation: Lemke, J.N.; Gallino, F.; Cresci, M.; Zilio, S.; Coda, A. Low-Hysteresis Shape Memory Alloy Scale-Up: DSC, XRD and

Microstructure Analysis on Heat-Treated Vacuum Induction Melted Ni-Ti-Cu-Pd Alloys. Metals 2021, 11, 1387. https://doi.org/ $10.3390 /$ met11091387

Academic Editor: Alexander V. Shelyakov

Received: 4 August 2021

Accepted: 27 August 2021

Published: 31 August 2021

Publisher's Note: MDPI stays neutral with regard to jurisdictional claims in published maps and institutional affiliations.

Copyright: (c) 2021 by the authors. Licensee MDPI, Basel, Switzerland. This article is an open access article distributed under the terms and conditions of the Creative Commons Attribution (CC BY) license (https:// creativecommons.org/licenses/by/ $4.0 /)$.
SAES Getters S.p.A., Viale Italia 77, 20020 Lainate, Italy; Federico_Gallino@saes-group.com (F.G.); matteo_cresci@saes-group.com (M.C.); Stefano_Zilio@saes-group.com (S.Z.);

Alberto_Coda@saes-group.com (A.C.)

* Correspondence: Jannis_Lemke@saes-group.com; Tel.: +39-02-93178-460

Abstract: Quaternary Ni-Ti-Cu-Pd formulations were cast by vacuum induction melting (VIM) with the aim of preparing low-hysteresis shape memory alloys and verifying the applicability of the Co-Factor theory in conventional industrial manufacturing processes. The cast alloys showed lower transformation hysteresis width in DSC measurements than binary Ni-Ti, but struggled to achieve a near zero hysteresis, as predicted by the theoretical framework, despite being close to satisfy the first Co-Factor condition (CC I) that foresees minimum hysteresis for formulations in which the middle eigenvalue of the martensitic transformation matrix $\lambda_{2}$ approaches one. The microstructure of the annealed Ni-Ti-Cu-Pd alloys exhibited a considerable amount of mostly sub-micron-sized secondary phases, which distort the matrix composition and prevent it from reaching the optimum stoichiometry for satisfying the CC I. In addition, this class of materials is prone to aging effects, leading to the formation of semi-coherent tetragonal precipitates, which tend to also form at the grain boundaries after low-temperature annealing, further affecting the transformation hysteresis in DSC experiments depending on the thermal history. This work reveals the importance of considering typical casting effects that alter the theoretical $\lambda_{2}$ of ideal materials in the compositional design for the development of high-performance low-hysteresis alloys.

Keywords: XRD; DSC; DFT; microstructure; Co-Factor theory; Ni-Ti-Cu-Pd; low-hysteresis shape memory alloys; heat treatments; vacuum induction melting

\section{Introduction}

Low-hysteresis shape memory alloys (LH-SMAs) are researched for a wide field of actuator applications [1], as a low hysteresis improves the actuation efficiency and is expected to significantly increase the fatigue life of devices [2]. Additionally, in orthodontic applications, low-hysteresis alloys are of interest as they could improve dental occlusion therapies [3]. The addition of $\mathrm{Cu}$ to binary $\mathrm{Ni}$-Ti is the most common alloying approach to decrease the thermal hysteresis between the high-temperature austenitic parent-phase and the low-temperature martensitic daughter-phase [4]. By increasing the amount of copper, the orthorhombic B19 martensite becomes continuously more stable over the monoclinic B19' allotropy form, which is the low-temperature phase in binary Ni-Ti. Previous research works indicated that by adding an amount of about 7.5 at. $\% \mathrm{Cu}$, the orthorhombic crystal structure occurs and that an altered transformation pathway B2 $\rightarrow$ B19 $\rightarrow$ B19' becomes stable during cooling up to a $\mathrm{Cu}$ content of approximately 15 at. \%, while at even higher $\mathrm{Cu}$ contents, a single B2 $\rightarrow$ B19 transformation is observed [5-7].

Presently, there exist several simulation works and experimental case studies, which proved that the amount of $\mathrm{Cu}$ in this span correlates well with a reduction in hysteresis. The theoretical background was established by J.M. Ball and R.D. James et al. [8], who introduced the elastic theory of martensite, implying that the thermal hysteresis approaches 
0 when the Co-Factor conditions are satisfied. Among those, the Co-Factor condition I (CC I), which refers to the middle eigenvalue of the martensitic transformation matrix reaching $\left|\lambda_{2}-1\right|=0$, is supposed to be the most significant [8-10]. Translated into physics, it means that matching these conditions guarantees a high compatibility between parentphase and daughter-phase, thus reducing the energy barrier at the austenite-martensite interphase to propagate during the transformation. For this reason, the thermal hysteresis becomes small, as lower energy is needed to switch between the two states. At the same time, fewer permanent dislocations are generated during the transformation, which leads to a higher cycling stability and deviation of characteristic transformation parameters.

However, one drawback of ternary $\mathrm{Ni}$-Ti-Cu alloys is that elevated $\mathrm{Cu}$ contents ( $\geq 15$ at. $\%$ ) are necessary for approaching the $\left|\lambda_{2}-1\right|=0$ condition, which might cause embrittlement due to the excessive formation of secondary phases [4]. By using combinations of four or more elements, this issue can be avoided. Based on this theoretical framework, several alloys were synthesized in previous work to obtain materials with minimized hysteresis, and the validity of the co-factor approach has been verified many times for various quaternary and even quinary Ni-Ti-Cu-X (-Y) systems [11,12]. Prominent examples are Ni-Ti-Cu-Co [2,13,14], Ni-Ti-Cu-Nb [15], Ni-Ti-Cu-Fe [16] and Ni-Ti-Cu-V [17,18].

Systems, which became particularly popular because they combine low-hysteresis width with high transformation temperature opportunities, are the Ni-Ti-Pd and Ni-Ti$\mathrm{Cu}-\mathrm{Pd}$ ones. Intensive research on the ternary system initiated in the early 1990s, and it remains a fascinating field of investigation for improving shape memory alloy performance today [19-22]. In these alloys, Pd usually substitutes for $\mathrm{Ni}$, and the microstructure remains near-monophasic close to the stoichiometric $\mathrm{Ti}:(\mathrm{Ni}+\mathrm{Pd}) \approx 1$ compositions $[19,20]$. Unlike most other alloying elements, which are added to Ni-Ti for reducing hysteresis, Pd additions do not decrease the transformation temperature; instead, at Pd contents above 10 at. $\%$ in alloys with $\mathrm{Ti} \geq 50$ at. \%, the temperatures rise continuously [4]. Besides affecting the transformation temperatures, $\mathrm{Pd}$ additions are also reported to modify the precipitation behavior; specifically, $\mathrm{Ni}-\mathrm{Ti}-\mathrm{Pd}$ alloys may contain $\mathrm{Ti}_{2} \mathrm{Pd}$ precipitates and the P-phase. The P-phase has a slightly Ti-poor composition and thus occurs above all in Ti-lean alloys and may form already at low temperatures, as shown by Hattori et al., cycling the Ni-Ti-Pd alloys up to $400{ }^{\circ} \mathrm{C}$ [22]. On the other hand, the same work and also Namigata et al. [21] attest these alloys high performance regarding dimensional stability, recovery ratio and work output during thermal cycling under stress due to the presence of the nanometer-sized precipitates.

The approach of combining Pd and $\mathrm{Cu}$ in Ni-Ti alloying could help to further tailor these materials for industrial applications. Zarnetta et al. demonstrated by a combinatorial thin-film approach that several quaternary formulations with near-zero hysteresis and a low amount of $\mathrm{Pd}$ (around 4.5 at. \%) can be found, reducing the cost of such alloys significantly [23]. In the same work, it was also shown that quaternary alloys are less sensitive in deviating the CC I condition from being satisfied by slight compositional changes than their ternary Ni-Ti-Pd and Ni-Ti-Cu counterparts. In addition, $\mathrm{Cu}$ is a versatile element in $\mathrm{Ni}-\mathrm{Ti}$ alloying. Ni-Ti-Cu alloys in moderate $\mathrm{Cu}$ quantities have a good workability and can be prepared using a wide elemental range of Ti-rich and Ti-lean formulations, as $\mathrm{Cu}$ substitutes typically for the minority element in the Ni-Ti matrix [24]. Furthermore, Ni-Ti$\mathrm{Cu}$ alloys also exhibit coherent precipitation behavior, which can be used for stabilizing cycling hysteresis and shape memory performance by heat treatments [10]. Due to the suitability and potential synergistic effects of using $\mathrm{Cu}$ and $\mathrm{Pd}$ in the scope of designing LH-SMAs, several works explored such quaternary systems. In particular, their precipitation behavior obtained a lot of attention to improve, similarly to ternary systems, the shape memory performance by coherent-phase matrix strengthening [25-28]. More precisely, two types of semi-coherent precipitates were reported to coexist in quaternary $\mathrm{Ni}-\mathrm{Ti}-\mathrm{Pd}-\mathrm{Cu}$ alloys: $\mathrm{Ti}_{2} \mathrm{Pd}$ and $\mathrm{Cu}$-rich $\mathrm{Ti}-\mathrm{Pd}-\mathrm{Cu}$ [25]. These precipitates were observed to be stable at temperatures above $500{ }^{\circ} \mathrm{C}$, making them more attractive than the ternary Ni-Ti-Pd alloys in applications where several thermal cycles are foreseen [26]. This is true even more so if 
high-temperature shape memory alloy (HT-SMA) applications are targeted, where thermal cycles significantly above $100{ }^{\circ} \mathrm{C}$ are necessary for triggering the transformation.

However, because of the high cost of Pd, there are only a few examples of studies that investigate on the transformation properties of cast ingots with an industrial relevant size. Literature works focus on low-scale thin-film approaches [23] or on arc melting, leading to fine microstructures with a matrix composition closer to the nominal total composition due to faster solidification than alloys prepared for industrially feasible commercial applications own [26]. The aim of this study is to design Ni-Ti-Cu-Pd LH-SMAs based on a density functional theory (DFT) approach considering Co-factor theory and prepare them by a scalable, vacuum-induction melting process, applying a typical post-annealing treatment for investigating on their industrial feasibility. To the knowledge of the authors, this study is the first one using this conventional melting process for the Ni-Ti-Cu-Pd alloy. Further solutions and aging heat treatments are applied to study the effect of precipitation on the microstructure and thermal stability.

\section{Materials and Methods}

The alloy design was based on two approaches, and accordingly, the studied alloys were divided into two groups designated by the letters " $\mathrm{A}$ " and " $\mathrm{B}$ ". Regarding group A, three formulations (Ti-rich, Ti 50 at. \%, Ti-lean) were inspired by the proposed compositions of patent US20060086432A1 by Z. Zhang and R. D. James, which foresees, based on the Co-Factor theory framework, minimum hysteresis whenever the following conditions are satisfied [29]:

$$
\begin{gathered}
\mathrm{Ti}=49.5-52.0 \text { at. } \% \\
\mathrm{Ti}=49.5-52.0 \text { at. } \% \\
\mathrm{Pd}=\left(10.8-0.011 \mathrm{Cu}^{2}\right) \pm 0.2 \text { at. } \% \\
\mathrm{Ni}=\text { balance }
\end{gathered}
$$

Furthermore, for group $\mathrm{B}$, the formula $\mathrm{Ti}_{50} \mathrm{Ni}_{38,3-x} \mathrm{Cu}_{11,5} \mathrm{Pd}_{x}$ was used to prepare three alloys (5-Pd, 15-Pd, 20-Pd), investigating the effect of Pd additions to a previously optimized ternary Ni-Ti-Cu LH-SMA for actuation applications [30].

DFT was applied to simulate the atomic structure and evaluate Co-factor conditions of the investigated alloys. A supercell of 128 atoms, obtained by an expansion matrix $4 \times 2 \times 4$, was used to simulate the cubic B2 and orthorhombic B19 cell of the austenitic parent-phase and the martensitic daughter-phase, respectively. The plane-wave-based Quantum ESPRESSO package was used [31]. Atoms were described by utrasoft pseudopotentials, and the Perdew-Burke-Ernzerhof (PBE) functional was adopted for the exchange and correlation interaction. For all calculations, energy cutoffs of $27 \mathrm{Ryd}$ and $270 \mathrm{Ryd}$ (for kinetic energy and charge density expansion, respectively) were implemented. The lattice parameters and the atomic positions were fully relaxed until the achievement of the convergence criteria of $10^{-3}$ a. u. for forces and $10^{-6}$ Ryd for energy within a $2 \times 2 \times 2 \mathrm{k}$-point mesh. The Co-Factor theory was applied to calculate the CC I, referring to the $\lambda_{2}$ eigenvalue of the transformation matrix and thus to the lattice compatibility between the austenitic and martensitic phases and the Co-Factor condition II (CC II), referring to the compatibility of the twin systems [9]. While satisfying both conditions leads to a reduction in the elastic transition layer during the transformation, the CC I was experimentally found to be of prior importance to reduce the thermal hysteresis and, therefore, will be discussed preferentially in the scope of this work [10]. The designed alloys and DFT calculation results are presented in Table 1.

The alloys were melted by VIM as cylindrical $400 \mathrm{~g}$ ingots with a $25 \mathrm{~mm}$ diameter. These ingots were then heat-treated in a vacuum furnace by $900{ }^{\circ} \mathrm{C}$ for $24 \mathrm{~h}$ in an inert Ar atmosphere for homogenization, followed by slow furnace cooling (cooling rate in order of $1-10{ }^{\circ} \mathrm{C} / \mathrm{min}$, hereafter referred to as "HOMO"). Small samples (50-100 mg) were cut and grinded to remove surface oxides for differential scanning calorimetry (DSC) 
and chemistry analysis. The combustion infrared absorption (CIA) method (using LECO analyzers) was used to guarantee that the amount of residual elements, such as $\mathrm{C}, \mathrm{N}$ and $\mathrm{O}$, are below $500 \mathrm{ppm}$. XRF analysis was performed to verify that the actual composition after melting represents the nominal composition with an error at least below 0.2 at. \% for each element. DSC measurements were carried out on samples from homogenized ingots, and after exposing them to solution treatment at $900{ }^{\circ} \mathrm{C} \times 30 \mathrm{~min}$, followed by water quenching and with additional aging treatment at $550{ }^{\circ} \mathrm{C}$ for $180 \mathrm{~min}$ in a muffle furnace (hereafter referred to as "HOMO", "ST" and "AGED", respectively). Cycling recipes and measurements with different thermal scanning rates were applied in the DSC analysis to study the transformation stability of alloys. At least three DSC runs were performed in order to assure that the error on the measured transformation temperature parameters was below $0.5^{\circ} \mathrm{C}$. In this work, the distance between the austenite finish and martensite finish temperatures $\Delta_{f} T$ is considered whenever referring to hysteresis width. Ingot sections were prepared by standard metallurgical cutting, mounting, grinding and polishing procedures. An etching reagent composed of $\mathrm{H}_{2} \mathrm{O}, \mathrm{HNO}_{3}$ and $\mathrm{HF}$ in a ratio of 5:4:1 was used to reveal microstructural features. A microstructure analysis was performed with an optical (OM) and a field-emission scanning electron microscope (FESEM). The crystal structure characterization was performed by X-ray diffraction (XRD, Panalytical $X^{\prime}$ Pert Pro instrument) using a theta-2theta configuration. The instrument was equipped with a $X^{\prime}$ Celerator $1 D$ sensor and employs $\mathrm{CuK}(\lambda=0.15418 \mathrm{~nm})$ radiation. The resulting spectra were evaluated by comparison to the JCPDS database, and a Pawley refinement was applied for a semi-quantitative evaluation of phases and the determination of lattice parameters.

Table 1. The nominal composition of experimentally melted alloys, the compositions for DFT calculations, and the results calculated for CC I and CC II; the closer these values are to zero, the more the conditions are satisfied. Alloys can be divided into two groups: Group A consists of alloys (Ti-rich, equiatomic, Ti-lean) with a content of $\mathrm{Pd}$ close to 10 at. \% and a $\mathrm{Cu} / \mathrm{Ni}$ ratio selected to minimize $\left|\lambda_{2}-1\right|$. Group B is composed by adding Pd in expense of Ni to the reference Ni-Ti-Cu LH-SMA alloy, data from [30].

\begin{tabular}{cccccccc}
\hline \multirow{2}{*}{ Alloy Group } & Code & Ti & Ni & Cu & Pd & $\begin{array}{c}\text { CCI: } \\
\text { I } \mathbf{2}_{\mathbf{2}}-\mathbf{1} \mid\end{array}$ & $\begin{array}{c}\text { CCII: Twins } \\
\text { Type I/II (1E-4) }\end{array}$ \\
\cline { 3 - 7 } & & & & & & \\
A & Ti-lean & 49.8 & 27.6 & 14 & 8.6 & & \\
DFT & & 50 & 27.3 & 14.1 & 8.6 & 0.0002 & $2.4-4.0$ \\
\hline A & Ti50 & 50 & 29.1 & 11.5 & 9.4 & & \\
DFT & & 50 & 28.9 & 11.7 & 9.4 & 0.0004 & $0.2-1.7$ \\
\hline A & Ti-rich & 50.2 & 30.9 & 9 & 9.9 & & \\
DFT & & 50 & 30.5 & 9.4 & 10.2 & 0.0003 & $1.4-2.8$ \\
\hline B & 5-Pd & 50.2 & 33.3 & 11.5 & 5 & & \\
DFT & & 50 & 33.6 & 11.7 & 4.7 & 0.0012 & $3.8-5.0$ \\
\hline B & 15-Pd & 50.2 & 23.3 & 11.5 & 15 & & \\
DFT & & 50 & 23.4 & 11.7 & 14.8 & 0.0009 & $16.6-18.6$ \\
\hline B & 20-Pd & 50.2 & 18.3 & 11.5 & 20 & & \\
DFT & & 50 & 18.0 & 11.7 & 20.3 & 0.0014 & $27.5-29.8$ \\
\hline
\end{tabular}

\section{Results}

\subsection{Group A Study-The Effect of Ti Content}

First, the transformation of homogenized alloys at $900{ }^{\circ} \mathrm{C}$ for $24 \mathrm{~h}$ with slow furnace cooling (HOMO), solution-treated alloys with water quenching at $900^{\circ} \mathrm{C}$ for $30 \mathrm{~min}$ after $\mathrm{HOMO}(\mathrm{ST})$ and aged alloys at $550{ }^{\circ} \mathrm{C}$ for $180 \mathrm{~min}$ after ST (AGED) were studied by 
DSC. DSC curves and transformation temperatures of the investigated alloys are shown in Figure 1a and Table 2, respectively.
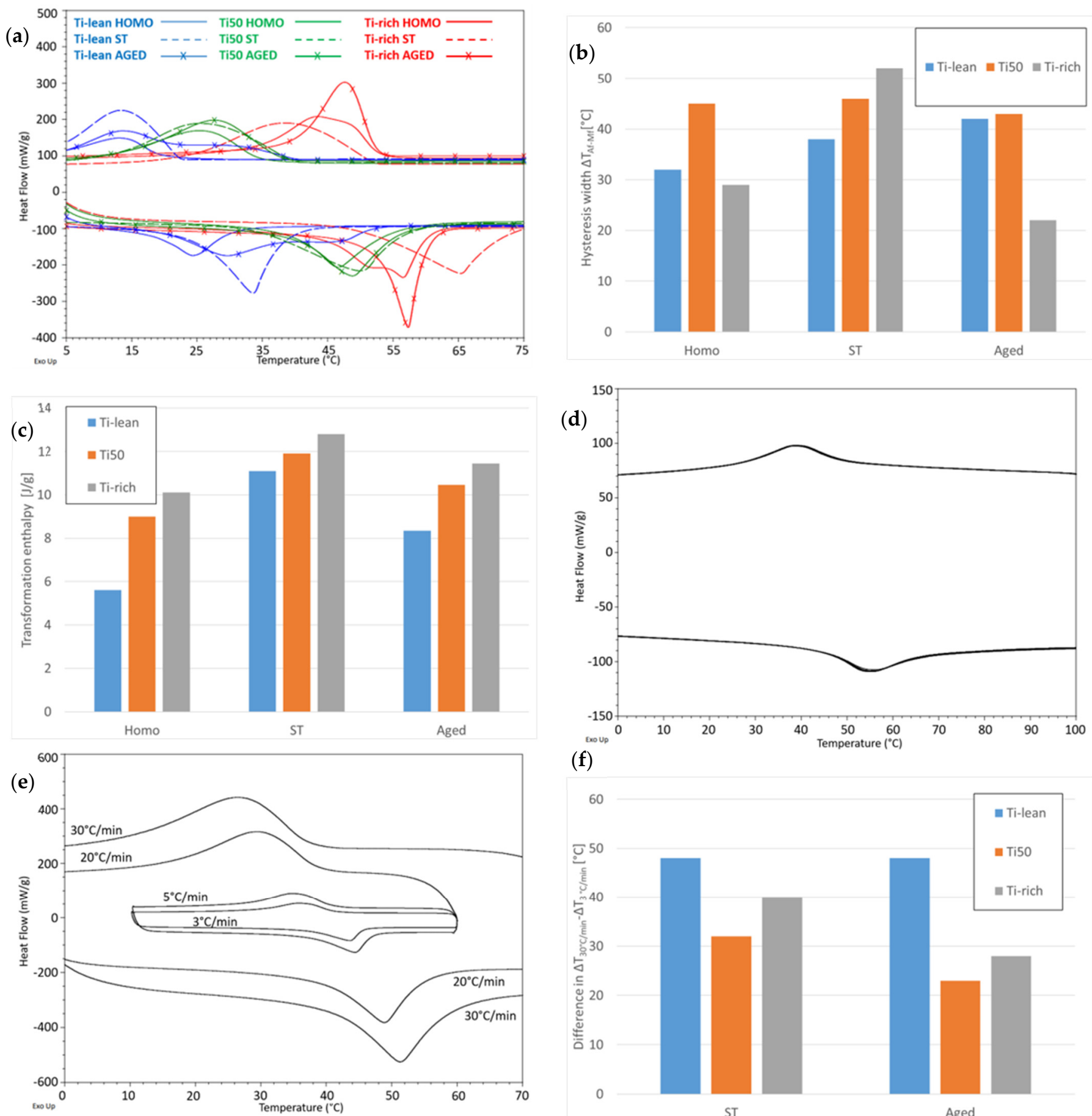

(f)

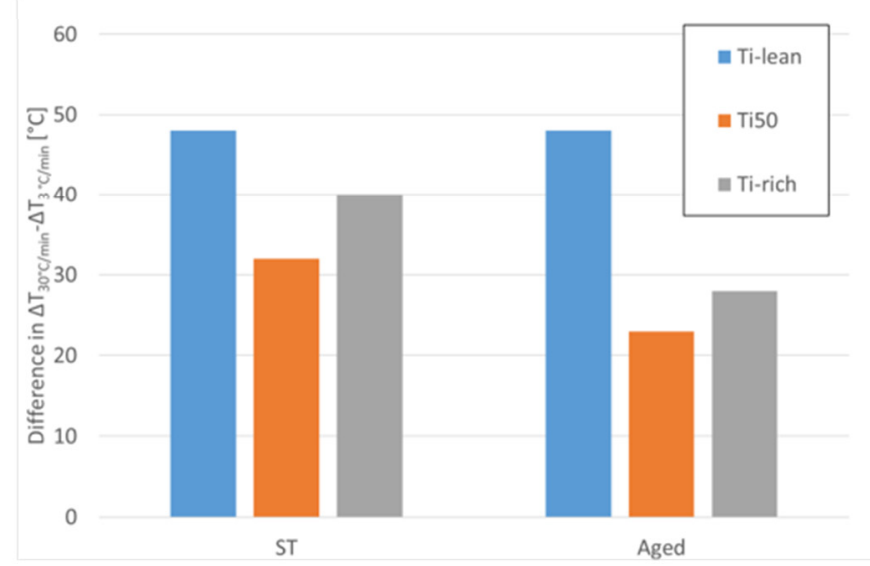

Figure 1. DSC results of group A alloys: (a) An overview of DSC curves after various heat treatments; (b) The hysteresis width of heat-treated alloys; (c) Enthalpy of transformation measured as the average of the forward and backward transformation; (d) A representative curve of the homogenized $\mathrm{Ti}_{50.2} \mathrm{Ni}_{30.9} \mathrm{Cu}_{9.0} \mathrm{Pd}_{9.9}$ exposed to ten DSC cycles; (e) A representative curve of solution-treated $\mathrm{Ti}_{50.0} \mathrm{Ni}_{29.1} \mathrm{Cu}_{11.5} \mathrm{Pd}_{9.4}$ cycled at different thermal rates ranging from $3-30{ }^{\circ} \mathrm{C} / \mathrm{min}$; (f) The growth of the hysteresis width by testing at $30^{\circ} \mathrm{C} / \mathrm{min}$ compared to $3{ }^{\circ} \mathrm{C} / \mathrm{min}\left(\Delta T_{30^{\circ} \mathrm{C} / \min }-\Delta T_{3^{\circ}} \mathrm{C} / \min \right)$. 
Table 2. Transformation temperatures as measured by DSC of homogenized, solution-treated and aged alloys A. The thermal rate was set to $10^{\circ} \mathrm{C} / \mathrm{min}$.

\begin{tabular}{|c|c|c|c|c|c|c|c|c|c|c|c|c|c|c|c|c|c|c|}
\hline \multirow{3}{*}{ Alloy } & \multicolumn{6}{|c|}{$900{ }^{\circ} \mathrm{C} \times 24 \mathrm{~h}(\mathrm{HOMO})\left({ }^{\circ} \mathrm{C}\right)$} & \multicolumn{6}{|c|}{$900^{\circ} \mathrm{C} \times 30 \min (\mathrm{ST})\left({ }^{\circ} \mathrm{C}\right)$} & \multicolumn{6}{|c|}{$550^{\circ} \mathrm{C} \times 180 \mathrm{~min}(\mathrm{AGED})\left({ }^{\circ} \mathrm{C}\right)$} \\
\hline & \multicolumn{6}{|c|}{ Furnace Cooled } & \multicolumn{6}{|c|}{ Water Quenched } & \multicolumn{6}{|c|}{ Water Quenched } \\
\hline & $\mathbf{A}_{\mathrm{s}}$ & $\mathbf{A}_{\mathbf{p}}$ & $\mathbf{A}_{\mathrm{f}}$ & $\mathbf{M}_{\mathrm{s}}$ & $\mathbf{M}_{\mathrm{p}}$ & $\mathbf{M}_{\mathrm{f}}$ & $\mathbf{A}_{\mathrm{s}}$ & $\mathbf{A}_{\mathrm{p}}$ & $\mathbf{A}_{\mathrm{f}}$ & $\mathbf{M}_{\mathrm{s}}$ & $\mathbf{M}_{\mathrm{p}}$ & $\mathbf{M}_{\mathrm{f}}$ & $\mathbf{A}_{\mathrm{s}}$ & $\mathbf{A}_{\mathrm{p}}$ & $\mathbf{A}_{\mathrm{f}}$ & $\mathbf{M}_{\mathrm{s}}$ & $\mathbf{M}_{\mathrm{p}}$ & $\mathbf{M}_{\mathrm{f}}$ \\
\hline Ti-lean & 16 & 24 & 31 & 20 & 13 & -1 & 23 & 34 & 39 & 21 & 13 & 1 & 21 & 30 & 44 & 23 & 14 & 4 \\
\hline Ti50 & 37 & 47 & 58 & 35 & 26 & 12 & 33 & 50 & 57 & 40 & 26 & 11 & 40 & 49 & 57 & 38 & 28 & 14 \\
\hline Ti-rich & 44 & 57 & 61 & 53 & 43 & 32 & 50 & 65 & 75 & 52 & 38 & 23 & 51 & 57 & 61 & 52 & 48 & 39 \\
\hline
\end{tabular}

The homogenized VIM cast alloys exhibit transformation temperatures with As ranging from $16{ }^{\circ} \mathrm{C}$ to $44^{\circ} \mathrm{C}$, increasing with Ti content, despite their coincidently higher Ni:Ti ratio (Figure 1a). Their transformation hysteresis (Figure 1b) width $A_{f}-M_{f}$ is significantly lower than in binary Ni-Ti VIM ingots $\left(\Delta_{f} T \approx 55-85^{\circ} \mathrm{C}\right)$ [32] but considerably higher than the results obtained in thin-film studies on such quaternary alloys [23]. After solution treatment, the transformation peaks tend to become broader, and the hysteresis increases. Subsequent aging treatment reduces the hysteresis significantly in the Ti-rich alloy and slightly in the Ti50 alloy, while it further increases in the Ti-lean alloy. Such effects can be explained by the precipitation behavior, as will be discussed in the following section.

The enthalpy of the transformation (Figure 1c) increases in all alloys after solution treatment, indicating that in the homogenized state, secondary phases are formed during slow furnace cooling and dissolve into the matrix phase after ST, leading to a higher fraction of material that participates actively in the transformation [11]. After the aging treatment, the enthalpy of the transformation decreases in all alloys again due to the formation of new secondary phases. The alloys showed in all conditions, HOMO, ST and AGED, a high stability upon thermal cycling. In ten DSC cycles, which covered the whole transformation, the peaks shifted less than $1{ }^{\circ} \mathrm{C}$, as demonstrated in Figure $1 \mathrm{~d}$, representatively for the Ti-rich alloy tested after the homogenization treatment. In order to investigate the dependence of the transformation parameters on the thermal scanning rate and in particular on hysteresis width, alloys were also tested at different DSC scanning rates of 3, 5, 20 and $30{ }^{\circ} \mathrm{C} / \mathrm{min}$. (Figure 1e illustrates the enlargement of peaks by increasing the thermal scanning rate.) It was shown before that the hysteresis enlarges in such alloys with the thermal rate, caused by the DSC measurement and intrinsic sample characteristics, affecting our perception of "small hysteresis" [32]. As shown in Figure 1f, the Ti-lean alloy is much more sensitive to a change in the scanning rate, the hysteresis is about $48^{\circ} \mathrm{C}$ higher testing at $30^{\circ} \mathrm{C} / \mathrm{min}$ than observed at a rate of $3{ }^{\circ} \mathrm{C} / \mathrm{min}$. On the other hand, the Ti50 alloy exhibits the smallest differences in hysteresis width by testing at fast and slow rates. The reasons for the differences in the sensitivity of alloys to the rate is not fully understood yet, as there does not seem to be a straight correlation to the $\left|\lambda_{2}-1\right|=0$ eigenvalue criterion of the CC I. However, it is striking that the rate sensitivity correlates well to the values calculated for the CC II in Table 1 for the three alloys. For CC II approaching zero, the hysteresis width becomes less affected by the heating and cooling velocity. Presumably, a higher compatibility of martensitic twin systems leads to accelerated transformation kinetics and hence a lower sensitivity to thermal delay at fast rates. The presence of coherent precipitates after aging could further support the transformation, as they act as nucleation sites for martensite and twins, further reducing the thermal sensitivity after aging.

The XRD spectra of homogenized and aged alloys measured at room temperature are shown in Figure 2.

The alloys contain several crystallographic phases at room temperature: B19 orthorhombic martensite, B2 cubic austenite and various tetragonal precipitates with different ideal stoichiometries $\left(\mathrm{Pd}_{5} \mathrm{Ti}_{3}, \mathrm{CuNiTi}\right.$, TiPdCu, CuTi). In all three alloys, $\mathrm{Pd}_{5} \mathrm{Ti}_{3}, \mathrm{TiPdCu}$ and CuTi phases are observed, while CuNiTi is only detected in the Ti-lean one. Due to the low furnace-cooling rate in the homogenization treatment, several precipitates are already present in the alloys prior to aging. However, after the solution treatment and 
subsequent annealing, the peaks of the tetragonal phases become much more evident, and the fraction of secondary phases significantly augments.. At a first glance, as the B2 [110] reflection is located around $41.8^{\circ}$, the samples seem to contain a significant amount of B2 austenite phases, and the ratio of B19 martensite to cubic B2 austenite increases after aging in correspondence to the increase in transformation temperatures reported in Table 2. However, this observation is counterintuitive to the DSC results presented in Figure 1, which demonstrated all samples — especially the Ti-rich sample — to be in a martensitic state at room temperature. In addition, a high quantity of residual B2 austenite is improbable, as the high transformation enthalpies values in Figure 1c indicate that samples transform completely and other B2 reflections in XRD spectra seem to be absent. It is known from ternary Ni-Ti-Cu alloys that there is a partial superposition of the B2 [110] and the B19 [020] peak [33]. For these reasons, we expect only a low quantity of residual B2 present in the samples, while the mere quantity of the peak is attributed to the B19 [020] planes reflections. The identification becomes even more difficult, as based on the content of the heavy Pd atoms, peaks are shifted increasingly to lower angles, rendering calibration procedures more complicated. However, it would be out of scope to quantify the B2:B19 ratio in this XRD study, which had the primary target of identifying precipitate phases and excluding the presence of other martensite morphologies (such as B19') in the alloys.

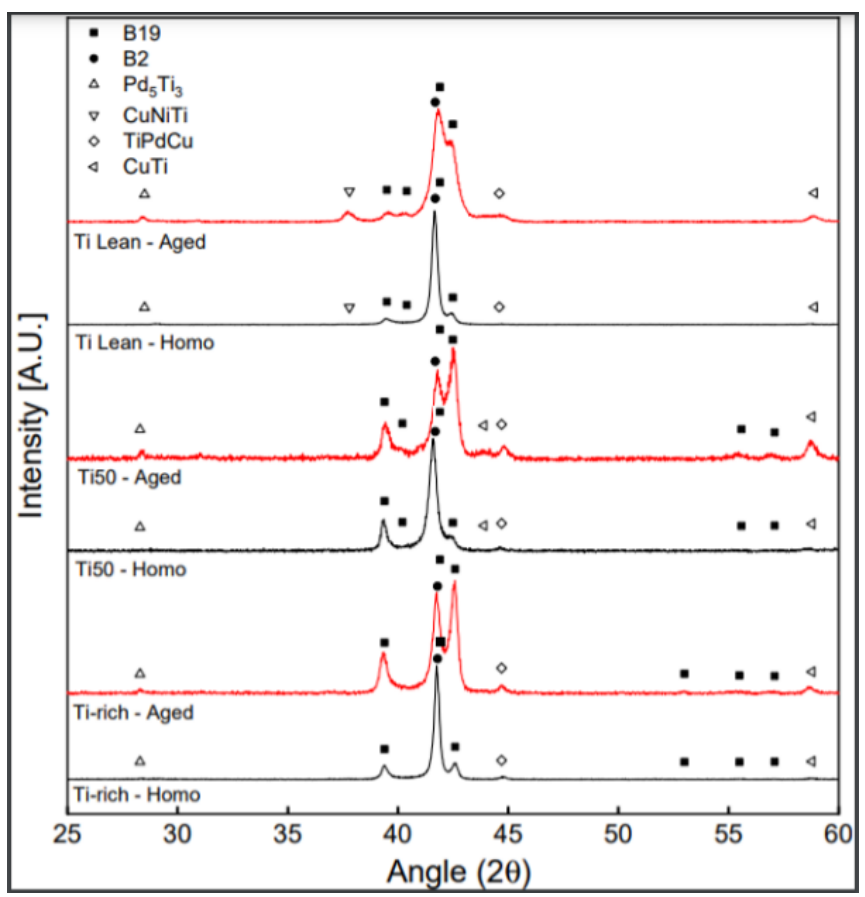

Figure 2. XRD Spectra of group A Ni-Ti-Cu-Pd alloys after homogenization $\left(900{ }^{\circ} \mathrm{C} \times 24 \mathrm{~h}\right)$ and aging $\left(550^{\circ} \mathrm{C} \times 3 \mathrm{~h}\right)$. Matrix phases are represented by plain symbols and tetragonal precipitates by open ones.

The microstructure of the VIM cast alloys shown in Figure 3 consists of austenitic grains in the $100 \mu \mathrm{m}-1 \mathrm{~mm}$ range in which, based on the transformation temperatures (c.f. Table 2), different quantities of martensitic twinned areas are observed at room temperature-the least in Ti-lean alloy (Figure 3a). All alloys contain some Ti-oxides and $\mathrm{Ti}_{2} \mathrm{Ni}$ inclusions, which were not revealed by XRD due to their small, localized amount. The higher resolution and back scattering contrast in SEM analysis reveal differences in the precipitation behavior of the alloys. In the Ti-lean (Figure 3d), only a few micronsized, macroscopic $\mathrm{Cu}$-rich precipitates are observed, which are sparsely distributed in the vicinity of the grain boundaries. The matrix seems free of macroscopic phases that can be revealed at these resolutions. On the other hand, in the Ti50 (Figure 3e) and Ti-rich alloy microstructure (Figure 3f), only finer, homogenously dispersed precipitates are present. 
Pd-rich precipitates, such as $\mathrm{Pd}_{5} \mathrm{Ti}_{3}$, which were identified by XRD (Figure 2) in all alloys, remain at the nanoscale and thus cannot be visualized by FE-SEM.
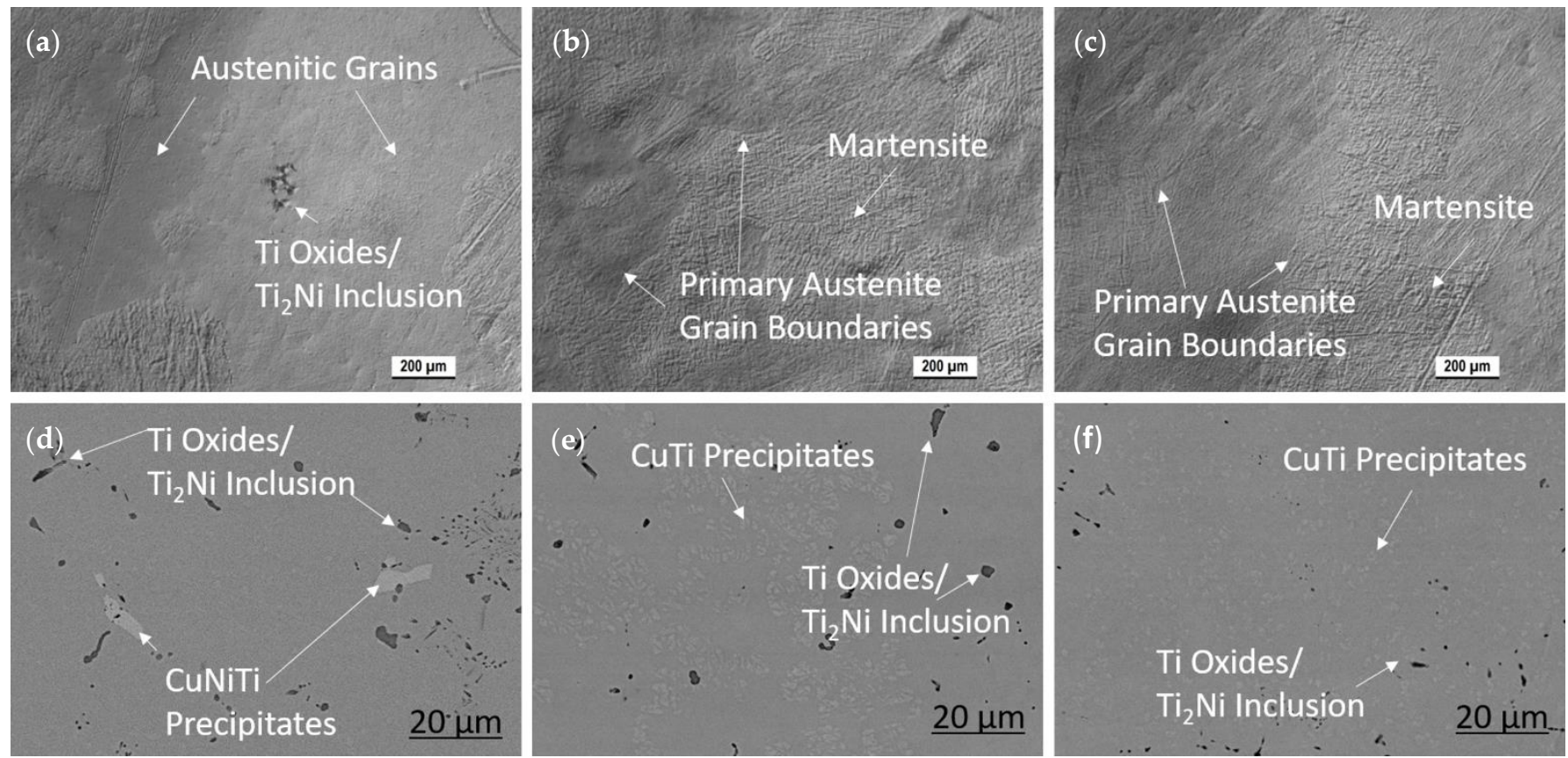

Figure 3. The microstructure of homogenized $\left(900{ }^{\circ} \mathrm{C} \times 24 \mathrm{~h}\right.$, Furnace cooled) group A VIM alloys: Optical and SEM micrographs of the (a,d) Ti-lean; (b,e) Ti50; and (c,f) Ti-rich alloys, respectively.

After the solution treatment and annealing at $550{ }^{\circ} \mathrm{C} \times 3 \mathrm{~h}$, no such semi-coherent macroscopic secondary phases are detected in the matrix, except the incoherent $\mathrm{Ti}_{2} \mathrm{Ni}$ precipitates, which are not soluble at $900{ }^{\circ} \mathrm{C}$ (Figure $4 \mathrm{a}, \mathrm{c}$ ). The solution treatment dissolved all coherent phases, and aging led to their reformation on a low nanometric scale in the matrix. However, close-up micrographs show that a thin layer of $\mathrm{Cu}$-rich phase with nm-range thickness formed along the grain boundary in all samples (Figure $4 \mathrm{~d}, \mathrm{f}$ ).
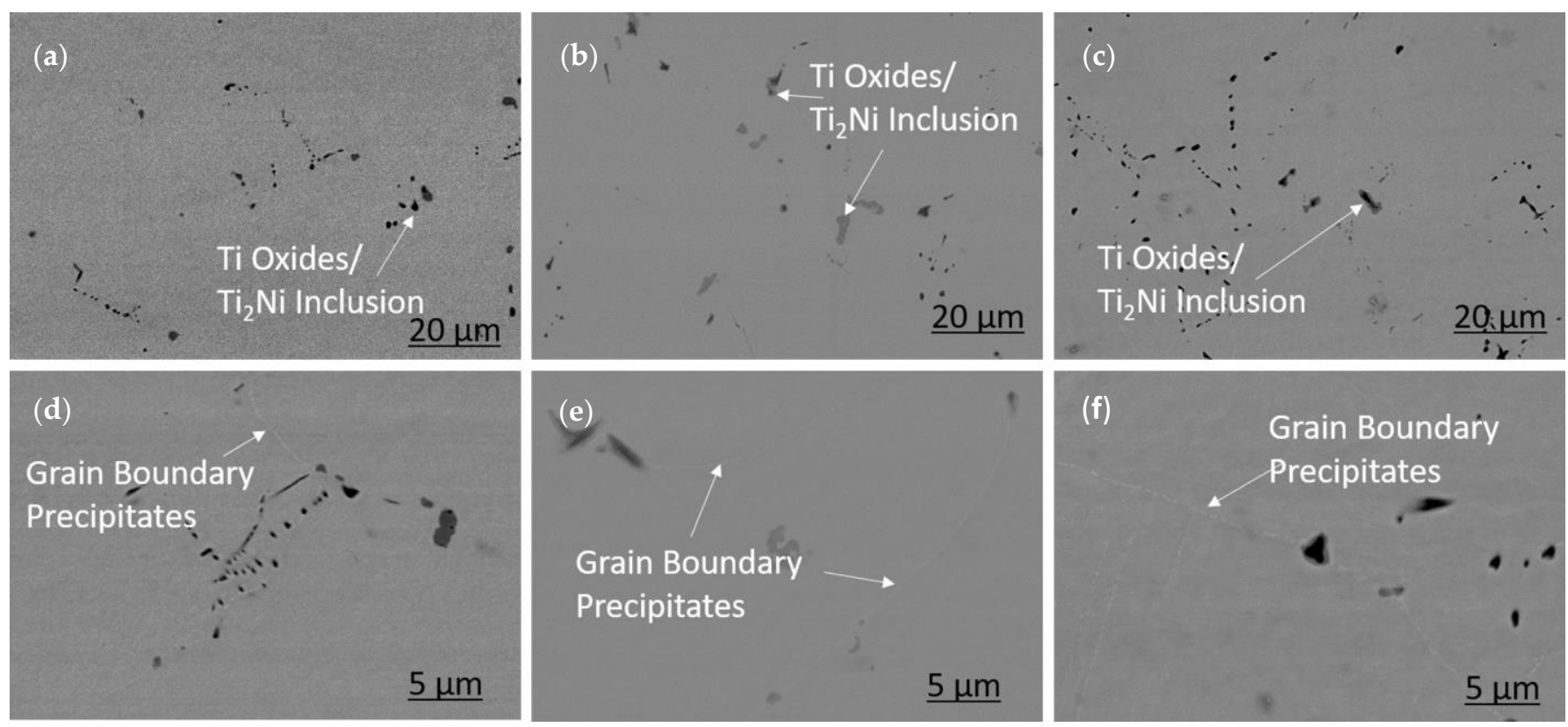

Figure 4. The microstructure of aged $\left(550{ }^{\circ} \mathrm{C} \times 3 \mathrm{~h}\right)$ group A VIM alloys: SEM micrographs of the (a,d) Ti-lean; (b,e) Ti50; and (c,f) Ti-rich alloys in two different magnifications. 


\subsection{Group B Study-The Effect of Pd Content}

Like for the alloys of group A, the transformation temperatures of the alloys with different $\mathrm{Pd}$ contents from group B were measured by DSC after homogenization at $900{ }^{\circ} \mathrm{C}$ for $24 \mathrm{~h}$ with slow furnace cooling, a solution treatment with water quenching at $900{ }^{\circ} \mathrm{C}$ for $30 \mathrm{~min}$ and aging at $550^{\circ} \mathrm{C}$ for $180 \mathrm{~min}$ after the solution treatment. The transformation temperatures of the investigated alloys are shown in Table 3.

Table 3. Transformation temperatures as measured by DSC of homogenized, solution-treated and aged alloys $\mathrm{B}$. Thermal rate was set to $10^{\circ} \mathrm{C} / \mathrm{min}$.

\begin{tabular}{|c|c|c|c|c|c|c|c|c|c|c|c|c|c|c|c|c|c|c|}
\hline \multirow{3}{*}{ Alloy } & \multicolumn{6}{|c|}{$\begin{array}{c}900{ }^{\circ} \mathrm{C} \times \underset{\left({ }^{\circ} \mathrm{C}\right)}{24 \mathrm{~h}}(\mathrm{HOMO}) \\
.\end{array}$} & \multicolumn{6}{|c|}{$\begin{array}{c}900^{\circ} \mathrm{C} \times 30 \min (\mathrm{ST}) \\
\left({ }^{\circ} \mathrm{C}\right)\end{array}$} & \multicolumn{6}{|c|}{$\begin{array}{c}550^{\circ} \mathrm{C} \times 180 \mathrm{~min}(\mathrm{AGED}) \\
\left({ }^{\circ} \mathrm{C}\right)\end{array}$} \\
\hline & \multicolumn{6}{|c|}{ Furnace Cooled } & \multicolumn{6}{|c|}{ Water Quenched } & \multicolumn{6}{|c|}{ Water Quenched } \\
\hline & $\mathbf{A}_{\mathrm{s}}$ & $A_{p}$ & $\mathbf{A}_{\mathrm{f}}$ & $\mathbf{M}_{\mathrm{s}}$ & $\mathbf{M}_{\mathrm{p}}$ & $\mathbf{M}_{\mathrm{f}}$ & $\mathbf{A}_{\mathbf{s}}$ & $A_{p}$ & $\mathbf{A}_{\mathrm{f}}$ & $\mathbf{M}_{\mathrm{s}}$ & $\mathbf{M}_{\mathrm{p}}$ & $\mathbf{M}_{\mathbf{f}}$ & $\mathbf{A}_{\mathrm{s}}$ & $A_{p}$ & $\mathbf{A}_{\mathbf{f}}$ & $\mathbf{M}_{\mathrm{s}}$ & $\mathbf{M}_{\mathrm{p}}$ & $\mathbf{M}_{\mathbf{f}}$ \\
\hline $5-\mathrm{Pd}$ & 77 & 85 & 90 & 77 & 70 & 62 & 54 & 71 & 80 & 54 & 40 & 26 & 66 & 76 & 83 & 73 & 64 & 50 \\
\hline 15-Pd & 56 & 63 & 67 & 56 & 52 & 44 & 74 & 86 & 93 & 75 & 68 & 57 & 56 & 63 & 67 & 56 & 52 & 44 \\
\hline 20-Pd & 119 & 131 & 135 & 124 & 116 & 103 & 124 & 141 & 151 & 121 & 106 & 89 & 124 & 132 & 136 & 122 & 116 & 107 \\
\hline
\end{tabular}

Similar to ternary Ni-Ti-Pd alloys [4], up to an elevated substitution of Ni for Pd, the transformation temperatures remain in a narrow range, then they start to increase continuously, as observed here for the alloy 20-Pd (Figure 5a,b). All alloys show a rather narrow transformation hysteresis, which does not lack behind the alloys of group A, despite the higher calculated CC I values (cf. Table 1). The DSC curves in Figure 5a and the effect of heat treatment on hysteresis in Figure $5 \mathrm{c}$ demonstrate a clear trend: after the solution treatment, the peaks become wider, and after aging, they decrease again, without showing a significant difference in width with respect to the homogenized transformations. The enthalpy of the transformation increases upon the solution treatment and returns to smaller dimensions after $550^{\circ} \mathrm{C}$ for the $3 \mathrm{~h}$ treatment, very similar to that observed for the alloys of group A. Additionally, in this case, the changes in enthalpy are related to the dissolution and reformation of secondary phases. The cycling stability is high, as shown in Figure 5e for cycling ten times the homogenized alloy 20-Pd, even though small shifts are observed, which could also be related to the cycling at higher temperatures, as $A_{f}$ is around $135^{\circ} \mathrm{C}$. The sensitivity to the thermal rate is investigated by cycling the alloys at rates ranging from $3-30{ }^{\circ} \mathrm{C} / \mathrm{min}$ and demonstrated representatively for the solution-treated alloy $20-\mathrm{Pd}$ (Figure 5f).

The spectra and designation of crystallographic phases of group B alloys are shown in Figure 6, as revealed by XRD analysis. All the alloys exhibit an almost fully B19 orthorhombic matrix structure as the analysis is performed significantly below their $M_{f}$ temperature, and only in 5-Pd, a tiny quantity of residual B2 is detected. Due to the much bigger $\mathrm{Pd}$ atom, which substitutes for $\mathrm{Ni}$, the crystals unit cell expands, and the peaks sustain a significant shift to lower angles with an increasing Pd amount. Besides the matrix phase, in group B alloys, precipitated secondary phases are also present after $900{ }^{\circ} \mathrm{C}$ for $24 \mathrm{~h}$ treatment and furnace cooling. Moreover, with a higher amount of $\mathrm{Pd}$, the intensity of reflections associated with precipitates in the homogenized samples increases. Most secondary phases in the three alloys are tetragonal and rich in $\mathrm{Cu}$; however, in the 15-Pd and 20-Pd alloys, a peak at $39.8{ }^{\circ} \mathrm{C}$ associated with $\mathrm{Pd}_{5} \mathrm{Ti}_{3}$ is measured, which grows significantly in size after a heat treatment at $550{ }^{\circ} \mathrm{C}$ for $3 \mathrm{~h}$, in particular for the latter alloy.

The microstructure of group B alloys is presented in Figure 7. The optical micrographs illustrate an evident change in the microstructure morphology of the almost completely martensitic samples (Figure 7a,c). The microstructure of 5-Pd resembles those of the group A alloys with fine twin features, and the primary austenite grain boundaries are clearly visible. Increasing the Pd content, the twin structure becomes coarser, in particular in the 20-Pd sample. Unlike in group A alloys, macroscopic matrix precipitates were not 
observed. The microstructures appear monophasic with a low amount of oxides and $\mathrm{Ti}_{2} \mathrm{Ni}$ inclusions. Only in 20-Pd, a low amount of $\mathrm{Cu}$-rich precipitates are present.
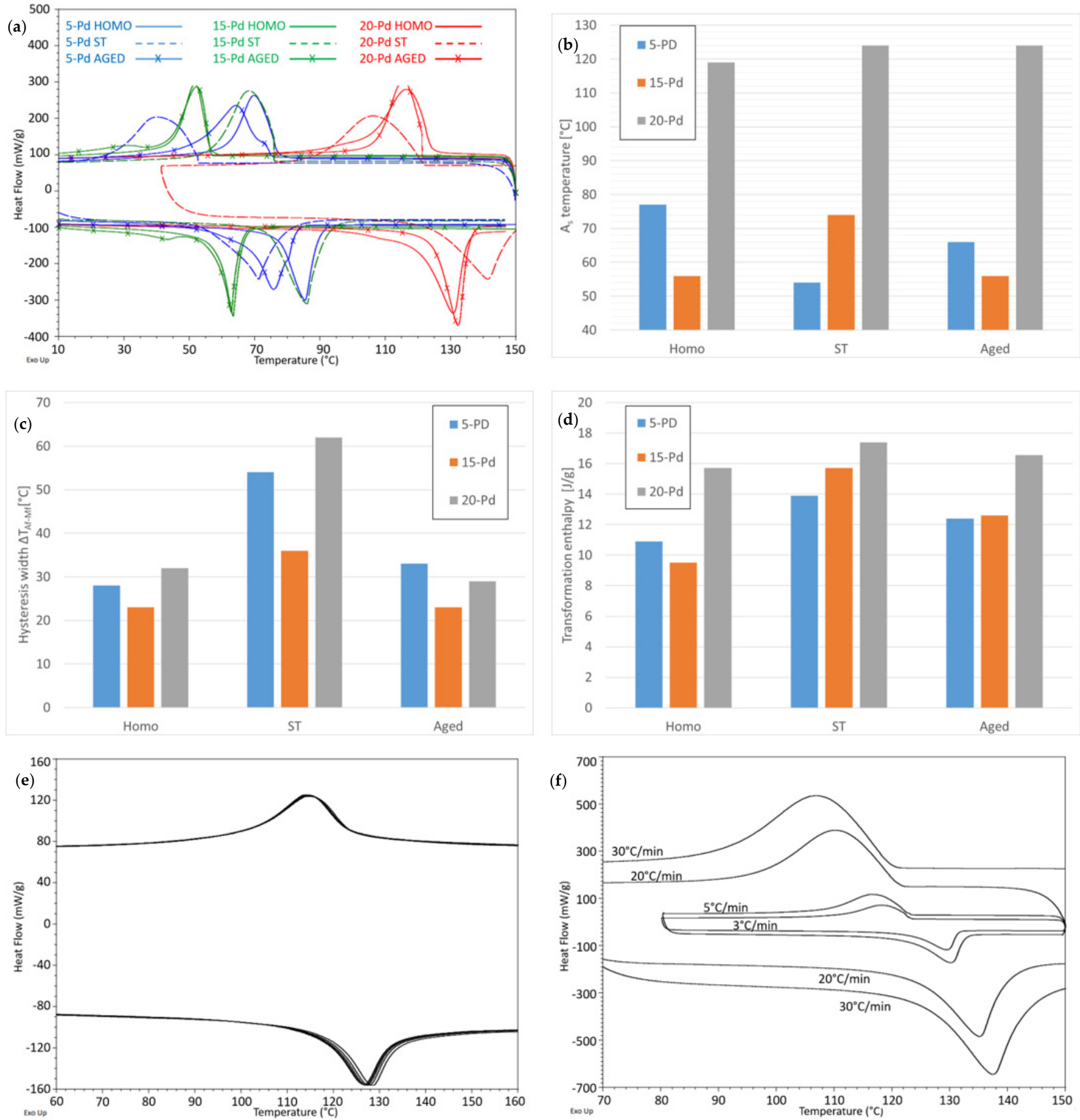

Figure 5. DSC results of alloy group B: (a) An overview of DSC curves after various heat treatments; (b) The austenitic transformation start temperature $A_{S}$ of heat treated alloys; (c) Hysteresis width of heat treated alloys, hysteresis is measured as difference between austenitic finish and martensitic finish temperature; (d) Enthalpy of the transformation measured as average of forward and backward transformation; (e) A representative curve of homogenized 20-Pd exposed to ten DSC cycles; (f) A representative curve of solution-treated 20-Pd cycled at different thermal rates ranging from $3-30{ }^{\circ} \mathrm{C} / \mathrm{min}$ $\left(\Delta T_{30^{\circ} \mathrm{C} / \mathrm{min}}-\Delta T_{3^{\circ} \mathrm{C} / \mathrm{min}}\right)$. 


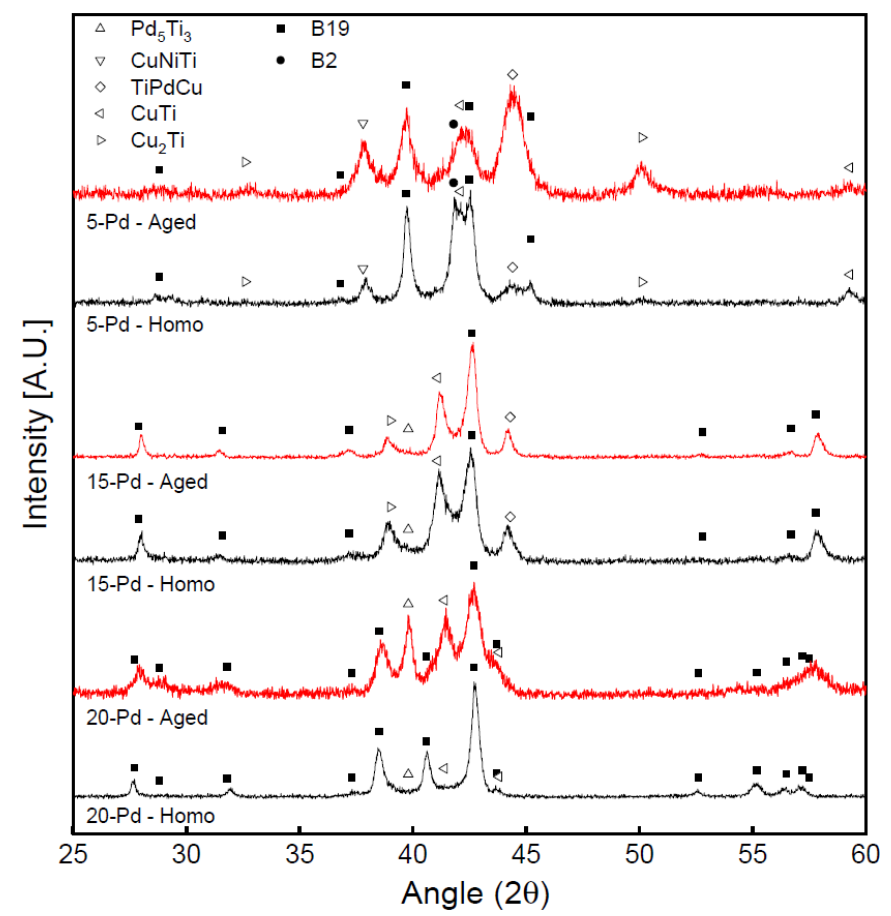

Figure 6. XRD spectra of group B Ni-Ti-Cu-Pd alloys after the homogenization $\left(900{ }^{\circ} \mathrm{C} \times 24 \mathrm{~h}\right)$ and aging $\left(550{ }^{\circ} \mathrm{C} \times 3 \mathrm{~h}\right)$ treatments. Matrix phases are represented by plain symbols and tetragonal precipitates by open ones.
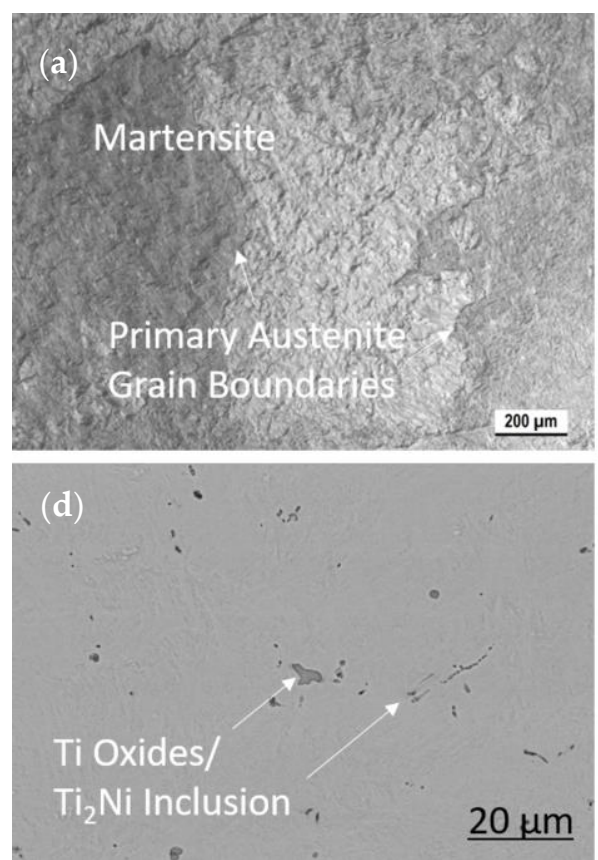
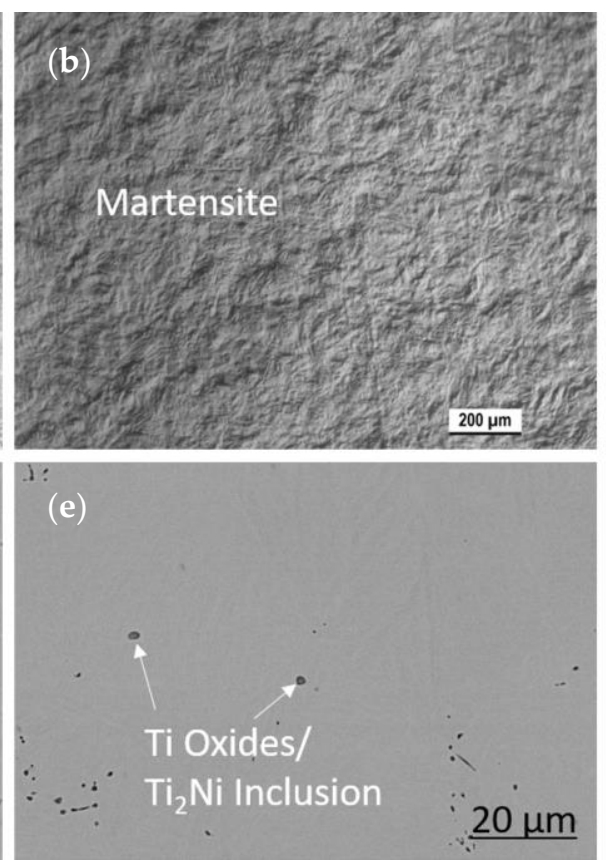
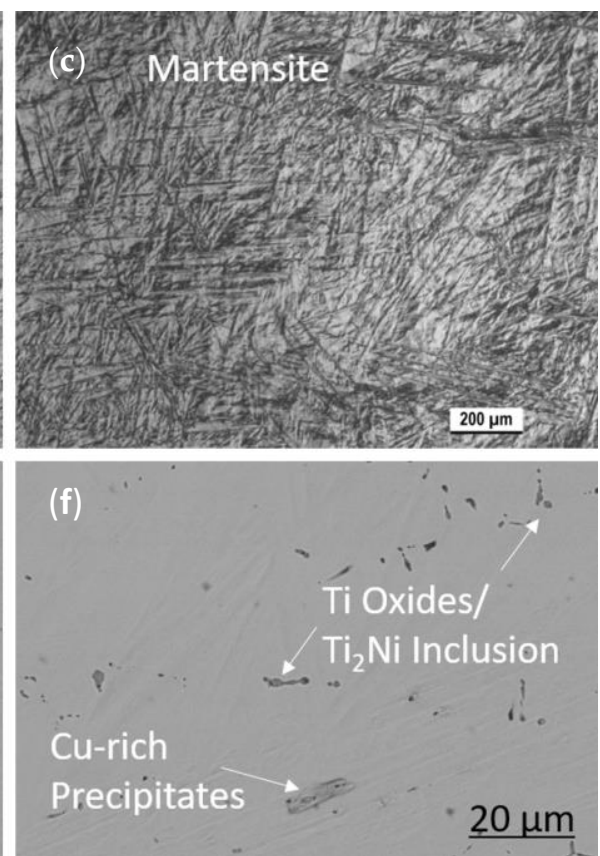

Figure 7. The microstructure of homogenized $\left(900{ }^{\circ} \mathrm{C} \times 24 \mathrm{~h}\right.$, Furnace cooled) group B VIM alloys: Optical and SEM micrographs of the (a,d) 5-Pd; (b,e) 15-Pd; and (c,f) 20-Pd alloys, respectively.

After the solution heat treatment followed by aging at $550{ }^{\circ} \mathrm{C}$ for $3 \mathrm{~h}$, no significant changes in the matrix are observed in the alloy 5-Pd (Figure 8a) and alloy 15-Pd (Figure 8b). However, in these alloys, precipitates are observed at the grain boundaries after aging (Figure $8 \mathrm{~d}, \mathrm{f}$ ). In the case of the 5-Pd alloy, where $\mathrm{CuNiTi}$ and $\mathrm{Cu}_{2} \mathrm{Ti}$ precipitates were predominantly found by XRD analysis, they show a unique bright contrast. On the other hand, in the 15-Pd and 20-Pd alloys, at least two types of submicron precipitates are 
revealed (Figure 8e,f): one Pd-rich type $\mathrm{Pd}_{5} \mathrm{Ti}_{3}$ and Cu-rich ones, which appear merely with a dark contrast compared to the matrix with a high amount of heavy Pd atoms. The formation of $\mathrm{Pd}_{5} \mathrm{Ti}_{3}$ precipitates causes a local depletion of $\mathrm{Pd}$ and thus an enrichment in $\mathrm{Cu}$; for this reason, they are found closely attached to $\mathrm{Cu}$-rich precipitates in alternating patterns. Rehman et al. found similar structures in higher Pd-containing alloys, in which $\mathrm{Ti}_{2} \mathrm{Pd}$ and $\mathrm{TiPdCu}$ were the main precipitates present [28].
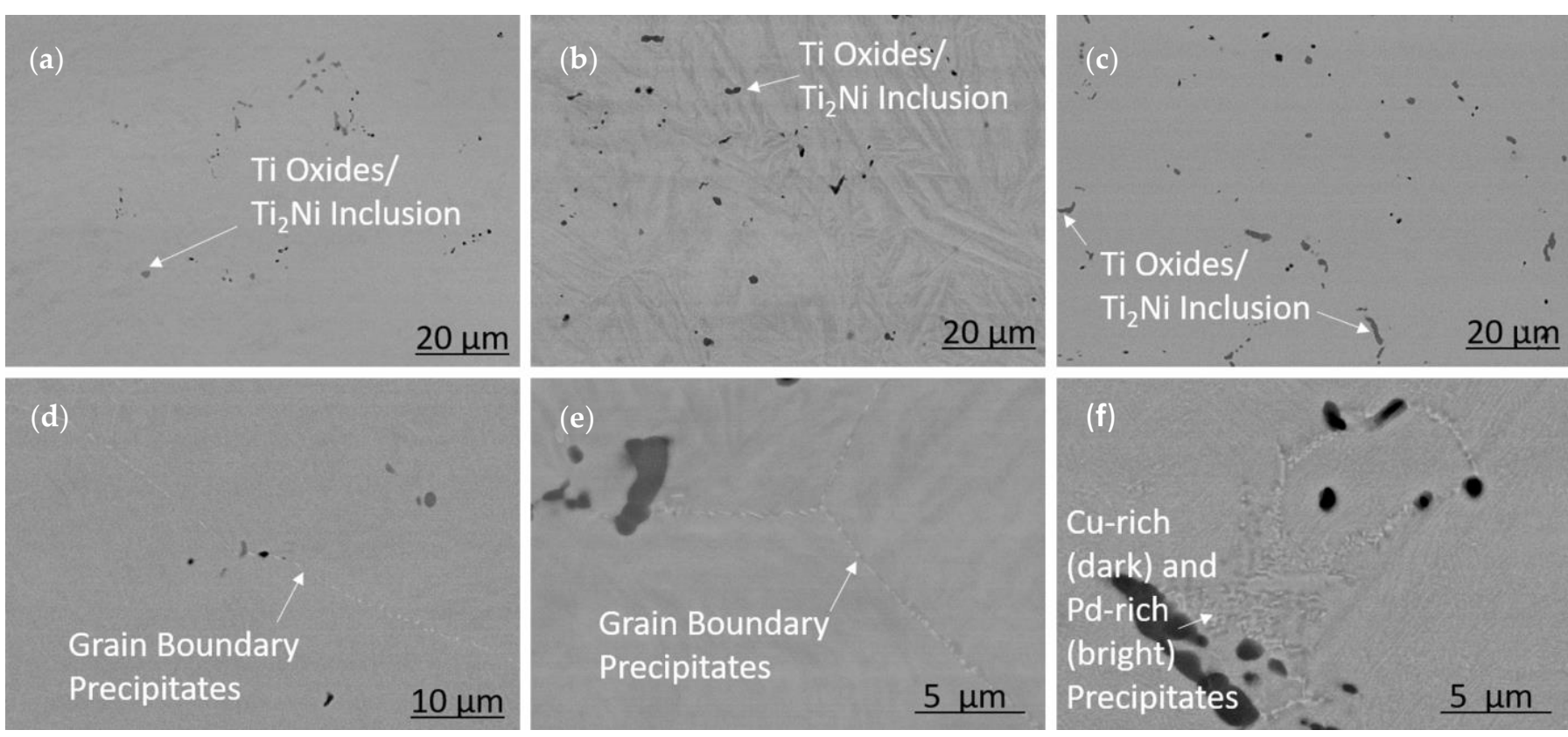

Figure 8. The microstructure of aged $\left(550{ }^{\circ} \mathrm{C} \times 3 \mathrm{~h}\right)$ group B VIM alloys: SEM micrographs of the $(\mathbf{a}, \mathbf{d})$ 5-Pd; $(\mathbf{b}, \mathbf{e}) 15-\mathrm{Pd}$; and (c,f) 20-Pd alloys in two different magnifications.

\section{Discussion}

The industrialization of higher alloyed shape memory alloys requires a minute control over the microstructure to guarantee processability, reliable mechanical properties, transformation behavior, excellent fatigue life and to fully exploit the low-hysteresis potential of these materials. It is known that not only the CC I Co-factor condition, which takes into account the chemistry, but also the microstructure, i.e., grain size, grain boundary orientation, presence of secondary phases etc. has an impact on the transformation properties of shape memory alloys [34]. In this regard, the use of conventional melting techniques, such as VIM, poses challenges to the realization of novel low-hysteresis alloys as solidification rates are much slower than in frequently explored low-scale synthetization processes, such as VAR, magneton sputtering or additive manufacturing. These techniques own far higher solidification rates than VIM, leaving most elements in solid solution of a fine-grained microstructure after synthesis. In order to estimate the solidification time of the VIM cast alloys of this work, Chvorinov's rule [35] was applied:

$$
t=B\left(\frac{V}{A}\right)^{n}
$$

where $t$ is the solidification time, $V$ the ingot volume, $A$ the contact area between the melt and $n$ a constant, which is empirically assumed to be 2 [35]. $B$ is the mold constant, which can be calculated according to Equation (6):

$$
B=\left[\frac{\rho_{m} L}{\left(T_{m}-T\right)}\right]^{2} \cdot\left[\frac{\pi}{4 k \rho c}\right] \cdot\left[1+\left(\frac{c_{m} \Delta T_{s}}{L}\right)^{2}\right]
$$


where $\rho$ and $\rho_{m}$ are the density of the mold and the metal, respectively, $T$ and $T_{m}$ are the temperature of the mold before pouring and the melting temperature of the liquid, $k$ is the thermal conductivity of the mold, $L$ is the latent heat of fusion, $c$ and $c_{m}$ are the specific heat capacity of the mold and the metal, and $\Delta T_{S}$ is the superheat of the liquid metal. A few approximations have been made, as the precise determination of these parameters is not trivial: the mold was assumed to be a perfect metallic carbon steel cylinder and the liquid metal in contact with the base area and the lateral surface. The mold constant was calculated using values for binary equiatomic NiTi. The used parameters are listed in Table 4.

Table 4. The parameters used to calculate the solidification time by means of Chvorinov's rule. The parameters were extracted from technical data sheets and scientific literature references [36,37].

\begin{tabular}{cccccc}
\hline$\rho\left(\mathrm{kg} / \mathrm{m}^{3}\right)$ & $K(\mathrm{~W} / \mathrm{mK})$ & $c(\mathrm{~J} / \mathrm{kgK})$ & $T(\mathrm{~K})$ & $N$ & $A\left(\mathrm{~mm}^{2}\right)$ \\
\hline 7600 & 25 & 470 & 298 & 2 & 5452 \\
\hline$\rho_{m}\left(\mathrm{~kg} / \mathrm{m}^{3}\right)$ & $L(\mathrm{~J} / \mathrm{kg})$ & $c_{m}(\mathrm{~J} / \mathrm{kgK})$ & $T_{m}(\mathrm{~K})$ & $\Delta T s(\mathrm{~K})$ & $V\left(\mathrm{~mm}^{3}\right)$ \\
\hline 6450 & 25,000 & 320 & 1583 & 70 & 62,015 \\
\hline
\end{tabular}

The calculation results in a mold constant of $\mathrm{B}=3964 \mathrm{~min} / \mathrm{cm}^{2}$ and a solidification time of $\mathrm{t}=307 \mathrm{~s}$. Depending on the alloy composition, which affects $c_{m}, \rho_{m}, T_{m}, \Delta T_{s}$, an error of up to $\pm 20 \%$ for the mold constant and solidification time is expected. However, even though the exact solidification time might vary depending on composition and simplifications of the system, the order of magnitude is in the range of several hundreds of seconds and thus much higher than all small-scale manufacturing processes, such as VAR, magnetron sputtering or processes that use a laser beam source for solidification of the alloy. For this reason, and due to the necessary high-temperature homogenization treatment, VIM ingots tend to be affected by the thermal history, which translates into different grain sizes and the presence of various secondary phases of different quantities and morphologies, as demonstrated here by XRD and SEM analysis, revealing $100 \mu \mathrm{m}$ sized grains and several tetragonal precipitates. From a technical point of view, these microstructural features may have many beneficial effects, e.g., precipitates can act as defect pinning sites and stabilize the transformation, as also observed here in the excellent DSC cycling behavior (cf. Figures $1 \mathrm{~d}$ and 5e). The approach and benefits of designing low-hysteresis SMA with excellent cycling behavior based on a high number of coherent nm-sized precipitates was demonstrated already in previous works, reporting on the enhancement of shape memory properties, cycling stability and fatigue life [2,10,38].

On the other hand, precipitation effects pose challenges to the design of LH-SMAs, as larger precipitates can act as crack initiators during cycling and secondary phases have a different composition than the matrix, thus modifying the composition of the transforming phase. Considering the high sensitivity of the Co-factor conditions, it seems impossible to satisfy them neatly in materials that "lose" matrix elements by the formation of incoherent secondary phases. These issues are amplified when the control over the precipitate presence and size distribution is limited, which becomes inherently more difficult in scaled-up alloy melting. In fact, the best thermal and mechanical cycling stability with near zero hysteresis was only demonstrated so far for alloys produced by thin-scale manufacturing methods, such as sputtering $[2,13,14]$. Another challenge in VIM microstructures arises from achieving a homogenous microstructure. The texture, distribution of grain size and tiny chemical inhomogeneities due to segregation at the grain boundaries are expected to occur on a higher level in comparison to the aforementioned technics, in particular in highly alloyed shape memory alloys [39]. Such effects might contribute to the slightly higher transformation hysteresis of the here-studied alloys than what was achieved in previous works [12]. However, depending on the amount of post-processing, these effects might become insignificant when working the material down to a semi-finished product, inducing reorientation of texture and grain refinement [34]. 
While the here-presented alloys, which according to the nominal composition are close to fulfilling the Co-factor conditions (especially group A), exhibit very promising transformation characteristics, particularly for larger-scale cast material, they do not reach a near-zero hysteresis due to their more complex microstructure. This is also reflected by the sensitivity of the DSC results on heat treatments: by solution treatment, precipitates dissolve into the matrix and cause tiny local differences in the composition, which enlarge the hysteresis. After aging, precipitates form and compensate for the compositional effects. Furthermore, the newly formed nano-sized precipitates can act as nucleation sites for the martensite transformation and, in this way, further reduce the hysteresis slightly. However, the formation of grain boundary precipitates after aging has to be seen critically, as they may cause embrittlement upon the subsequent processing of the alloys by forging or drawing.

The only alloy, which demonstrated an opposite trend, was the Ti-lean one. The reason, therefore, is assumed to lie in its different precipitation behavior, owing to a $\mathrm{Ti}$ content below 50 at. \%, which led to the formation of several micron-sized Cu-rich CuNiTi precipitates. Their dissolution causes higher compositional gradients in the matrix and enlarges the hysteresis upon aging.

Lattice parameters, as measured by $\mathrm{XRD}$, for alloys of group $\mathrm{A}$ and group $\mathrm{B}$ are shown in Figure 9a,b, respectively. Despite group A alloys being designed for fulfilling precisely the cofactor condition CC I, the geometries of the B19 cell vary significantly, which is another way to illustrate the sensitivity of the system to the composition. On the other hand, in the case of group B alloys, where Pd substitutes for Ni, clear trends for lattice parameters are observed as the cell volume increases with the content of $\mathrm{Pd}$.

The discrepancy between the ideal crystal structure for fulfilling the $\lambda_{2}$-criteria and the actual alloy crystal structure also becomes evident by comparing the lattice parameters of the cubic B2 austenite and orthorhombic B19 martensite cells calculated by DFT and the results measured by XRD. The lattice expansion by $\mathrm{Cu}$ and $\mathrm{Pd}$ inclusion has been computationally evaluated by fully optimizing a supercell of 128 atoms starting from NiTi lattice parameters. $\mathrm{Cu}$ and $\mathrm{Pd}$ atoms have been randomly placed in the Ni-sublattice with atomic compositions close to the experimental ones, as reported in Table 1. The evolution of the difference of the measured and calculated lattice parameters with increasing amounts of Pd (group B alloys) is shown in Figure 9c. It is evident that the empirically determined lattice parameters differ from the predictions made by DFT. While XRD and DFT results for the cubic B2 lattice parameter coincide to $\pm 0.1 \AA$, the difference becomes significantly bigger for the B19 parameters. The calculation tends to predict a smaller value for the short edge $b$ and slightly larger values for the longest edge a. The error seems to become smaller and invert with a higher $\mathrm{Pd}$ content. One reason for the trend could be that secondary precipitates are predominantly $\mathrm{Cu}$ - and $\mathrm{Pd}$-rich, and the more of these phases are present, the bigger becomes the deviation from the calculations, which, in DFT, assume that all elements are dissolved in the matrix phase.

One last aspect, which should be highlighted here, is the effect of satisfying the CC II criteria, which got little attention in the literature up to today. No evidence was found in this work that there is a notable correlation between CC II and hysteresis width; however, it was observed that those alloys with a low CC II showed very stable cycling behavior, and the criteria seems also correlated to the microstructure observations. The alloys that are further from CC II $=0$ show a more coarsely twinned martensitic structure with clearly visible needles. It is hypothesized that fulfilling these criteria supports twin accommodation, hence accelerating transformation kinetics and reducing the thermal offset in DSC cycling. However, more investigation is needed here, as experiments were not designed to primarily investigate on this effect. Furthermore, applying phase field studies that take into account multi-variants of martensite during the transformation, as they are emerging recently [40], could be taken in consideration to obtain a deeper understanding of the peculiarities in the B2-B19 phase transformation of Ni-Ti-Cu-Pd alloys. 

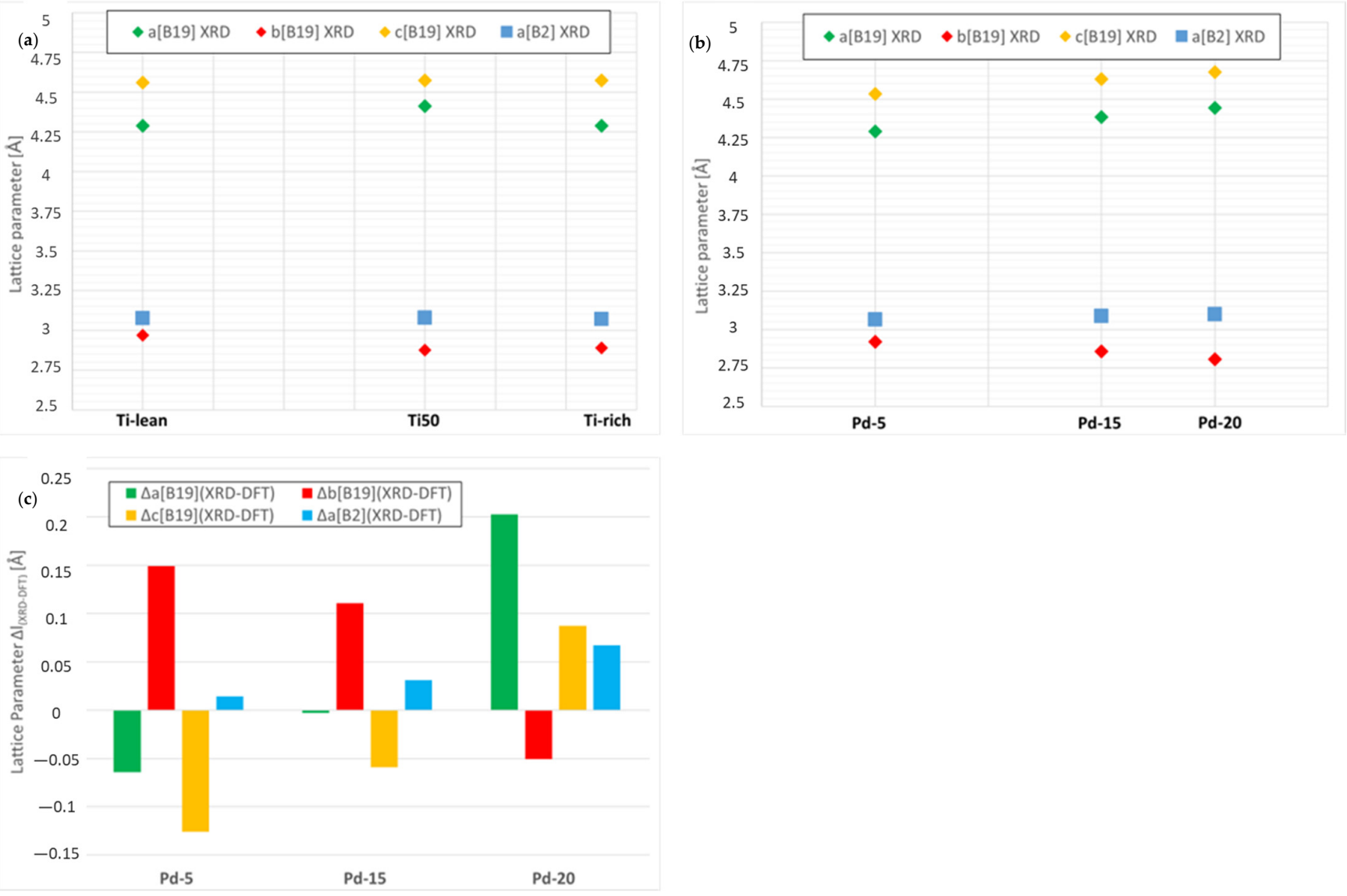

Figure 9. XRD Lattice parameters measured by XRD for homogenized alloys of: (a) group A and (b) group B; (c) the difference between the lattice parameters measured by XRD and calculated by DFT for alloys of group B.

\section{Conclusions}

This research sheds light on the transformation properties of Ni-Ti-Cu-Pd alloys, as prepared by a conventional vacuum induction melting and annealing approach for $\mathrm{LH}-$ SMA applications. The technical feasibility of such an approach depends on whether the low-hysteresis, high-thermal cycling stability and high-temperature capabilities of these alloys known from small-scale preparation can be maintained at a bigger ingot scale. This work illustrates the challenges in controlling the microstructure to achieve the expected lowhysteresis behavior. Satisfying the Co-factor conditions in the preparation of larger scale alloys seems to be the most challenging, which, due to the process nature and necessary heat treatments, have a non-ideal, multiphase microstructure. However, despite failing to replicate the same excellent transformation behavior achieved in thin-film studies, the here-presented results give rise to optimism that by considering the melting and annealing effects in alloy design, high-performance Ni-Ti-Cu-Pd alloys can be VIM manufactured based on a Co-factor approach. In the following, a summary of the main conclusions:

- Homogenized VIM cast Ni-Ti-Cu-Pd alloys exhibit a non-equilibrium microstructure of a B2/B19 matrix phase with the unavoidable presence of secondary phases. $\mathrm{XRD}$ and microscopy analysis revealed the presence of different secondary phases in the melted ingots. Low-melting point tetragonal precipitates were found in all $\mathrm{Ni}$-Ti-Cu-Pd alloys. Most frequently observed were semi-coherent, nanometer-sized $\mathrm{Pd}_{5} \mathrm{Ti}_{3}, \mathrm{Cu}_{2} \mathrm{Ti}, \mathrm{CuTi}$ and $\mathrm{Cu}$-rich $\mathrm{CuTiNi} / \mathrm{CuTiPd}$ precipitates. Furthermore, small amounts of Ti-oxides were present in all formulations, which act as nucleation sites for macroscopic (several $\mu \mathrm{m}$ ), incoherent $\mathrm{Ti}_{2} \mathrm{Ni}$ and $\mathrm{Ti}_{2} \mathrm{Cu}$ precipitates with a high melting point above $1100^{\circ} \mathrm{C}$. 
- Despite low cooling rates $\left(1-10^{\circ} \mathrm{C} / \mathrm{min}\right)$ of furnace cooling after the homogenization treatment, the content of the secondary phases still increased after the solution treatment and aging at $550{ }^{\circ} \mathrm{C} \times 3 \mathrm{~h}$, confirming a metastable state of homogenized VIM cast alloys.

- This metastable state causes significant deviations in the matrix chemistry from the overall composition. A non-proportional amount of the elements will be dissolved in high melting point precipitates and oxides and deteriorate the matrix composition. Another quantity of elements is distributed in semi-coherent precipitates, which form and can be dissolved by applying heat treatments. Therefore, the highly sensitive Co-Factor condition $\left|\lambda_{2}-1\right|=0$ is difficult to match, and the correlation with calculated/measured $\lambda_{2}$ and thermal hysteresis in the here-tested alloys was low. New models that predict the change in the matrix composition due to the formation and precipitation of non-shape memory phases needs to be developed and applied to counterbalance the described effect in the design of alloys.

- In VIM cast alloys, the solution treatment with subsequent aging seemed an effective strategy for most formulations to further reduce hysteresis. However, precipitates tend to enrich also at the grain boundaries, which is expected to impact the workability of the alloys. In particular, in the high Pd-containing alloys, where two different types of precipitates were observed at the grain boundaries, the processability could be compromised after low-temperature annealing.

- An apparent correlation between CC II, martensitic morphology and thermal cycling stability was observed. The here-presented results hint at finer martensite features and higher thermal cycling stability when CC II approaches 0 . However, these observations need to be further confirmed as the experiments were not designed to principally investigate this hypothesis.

The next step for future investigation is to convert these materials by processing into semi-finished products, such as wire, sheets or springs, to assess their workability and feasibility as actuation devices.

Author Contributions: Conceptualization, A.C. and J.N.L.; computational results, F.G.; experimental, M.C. and J.N.L., writing—original draft preparation, J.N.L.; writing—review and editing, A.C., S.Z., F.G. and M.C., supervision, A.C. All authors have read and agreed to the published version of the manuscript.

Funding: This research received no external funding.

Institutional Review Board Statement: Not applicable.

Informed Consent Statement: Not applicable.

Data Availability Statement: Not applicable.

Acknowledgments: The authors would like to thank E. Rizzi from SAES Getters S.p.A. for the support in data preparation and the SAES Getters S.p.A.

Conflicts of Interest: The authors declare no conflict of interest.

\section{References}

1. Huang, W. On the selection of shape memory alloys for actuators. Mater. Des. 2002, 23, 11-19. [CrossRef]

2. Chluba, C.; Ge, W.; de Miranda, R.L.; Strobel, J.; Kienle, L.; Quandt, E.; Wuttig, M. Ultralow-fatigue shape memory alloy films. Science 2015, 348, 1004-1007. [CrossRef]

3. Gil, F.J.; Planell, J.A. Effect of copper addition on the superelastic behavior of Ni-Ti shape memory alloys for orthodontic applications. J. Biomed. Mater. Res. Appl. Biomater. 1999, 48, 682-688. [CrossRef]

4. Duerig, T.; Pelton, A.; Trepanier, C. "Nitinol: The Book." Part 1, Mechanisms and Behavior; ASM International: Novelty, OH, USA, 2011.

5. Nam, T.H.; Saburi, T.; Shimizu, K. Cu-content dependence of shape memory characteristics in Ti-Ni-Cu alloys. Mater. Trans. JIM 1990, 31, 959-967. [CrossRef]

6. Tang, W.; Sandström, R.; Wei, Z.G.; Miyazaki, S. Experimental Investigation and Thermodynamic Calculation of the Ti-Ni-Cu Shape Memory Alloys. Metall. Mater. Trans. A 2000, 31, 2423-2430. [CrossRef] 
7. Callisti, M.; Tichelaar, F.D.; Mellor, B.G.; Polcar, T. Effects of $\mathrm{Cu}$ on the microstructural and mechanical properties of sputter deposited Ni-Ti thin films. Surf. Coat. Technol. 2013, 237, 261-268. [CrossRef]

8. Ball, J.M.; James, R.D. Fine phase mixtures as minimizers of energy. Arch. Ration. Mech. Anal. 1987, 100, 13-52. [CrossRef]

9. Chen, X.; Srivastava, V.; Dabade, V.; James, R.D. Study of the cofactor conditions: Conditions of supercompatibility between phases. J. Mech. Phys. Solids 2013, 61, 2566-2587. [CrossRef]

10. Gu, H.; Bumke, L.; Chluba, C.; Quandt, E.; James, R.D. Phase engineering and supercompatibility of shape memory alloys. Mater. Today 2018, 21, 265-277. [CrossRef]

11. Frenzel, J.; Wieczorek, A.; Opahle, I.; Maaß, B.; Drautz, R.; Eggeler, G. On the effect of alloy composition on martensite start temperatures and latent heats in Ni-Ti-based shape memory alloys. Acta Mater. 2015, 90, 213-231. [CrossRef]

12. Tong, Y.; Shuitcev, A.; Zheng, Y. Recent development of TiNi-based shape memory alloys with high cycle stability and high transformation temperature. Adv. Eng. Mater. 2020, 22, 1-15. [CrossRef]

13. Chluba, C.; Ossmer, H.; Zamponi, C.; Kohl, M.; Quandt, E. Ultra-low fatigue quaternary TiNi-based films for elastocaloric cooling. Shape Mem. Superelasticity 2016, 2, 95-103. [CrossRef]

14. Chluba, C.; Ge, W.; Dankwort, T.; Bechtold, C.; de Miranda, R.L.; Kienle, L.; Wuttig, M.; Quandt, E. Effect of crystallographic compatibility and grain size on the functional fatigue of sputtered TiNiCuCo thin films. Philos. Trans. R. Soc. A Math. Phys. Eng. Sci. 2016, 374, 20150311. [CrossRef] [PubMed]

15. Tong, Y.; Gu, H.; James, R.D.; Qi, W.; Shuitcev, A.V.; Li, L. Novel TiNiCuNb shape memory alloys with excellent thermal cycling stability. J. Alloys Compd. 2019, 782, 343-347. [CrossRef]

16. Xue, D.; Balachandran, P.V.; Hogden, J.; Theiler, J.; Xue, D.; Lookman, T. Accelerated search for materials with targeted properties by adaptive design. Nat. Commun. 2016, 7, 11241. [CrossRef]

17. Schmidt, M.; Ullrich, J.; Wieczorek, A.; Frenzel, J.; Schütze, A.; Eggeler, G.; Seelecke, S. Thermal stabilization of NiTiCuV shape memory alloys: Observations during elastocaloric training. Shap. Mem. Superelast. 2015, 1, 132-141. [CrossRef]

18. Al Hasan, N.M.; Hou, H.; Sarkar, S.; Thienhaus, S.; Mehta, A.; Ludwig, A.; Takeuchi, I. Combinatorial synthesis and highthroughput characterization of microstructure and phase transformation in NiTiCuV quaternary thin-film library. Engineering 2020, 6, 637-643. [CrossRef]

19. Lindquist, P.G.; Wayman, C.M. Transformation behavior of Tri50.(Ni (5o-x) Pdx) and Tisa-(Ni (5o-x) Ptx) alloys. MRS Int'l. Mtg. Adv. Mats 1989, 9, 129-134.

20. Lapin, V.B.; Egorushkin, V.E.; Shabalovskaya, S.A.; Ivanova, O.P. Electronic structure of TiNi, TiPd, and Ti (Ni1-xPdx) alloys. Solid State Commun. 1990, 73, 471-475. [CrossRef]

21. Namigata, Y.; Hattori, Y.; Khan, M.I.; Kim, H.Y.; Miyazaki, S. Enhancement of shape memory properties through precipitation hardening in a Ti-Rich Ti-Ni-Pd high temperature shape memory alloy. Mater. Trans. 2016, 57, 241-249. [CrossRef]

22. Hattori, Y.; Taguchi, T.; Kim, H.Y.; Miyazaki, S. Effect of stoichiometry on shape memory properties and functional stability of Ti-Ni-Pd alloys. Materials 2019, 12, 798. [CrossRef] [PubMed]

23. Zarnetta, R.; Takahashi, R.; Young, M.L.; Savan, A.; Furuya, Y.; Thienhaus, S.; Maaß, B.; Rahim, M.; Frenzel, J.; Brunken, H.; et al. Identification of quaternary shape memory alloys with near-zero thermal hysteresis and unprecedented functional stability. Adv. Funct. Mater 2010, 20, 1917-1923. [CrossRef]

24. Singh, N.; Talapatra, A.; Junkaew, A.; Duong, T.; Gibbons, S.; Li, S.; Thawabi, H.; Olivos, E.; Arróyave, R. Effect of ternary additions to structural properties of NiTi alloys. Comput. Mater. Sci. 2016, 112, 347-355. [CrossRef]

25. Imahashi, M.; Khan, M.I.; Kim, H.Y.; Miyazaki, S. The effect of Pd content on microstructure and shape-memory properties of Ti-Ni-Pd-Cu alloys. Mater. Sci. Eng. A 2014, 602, 19-24. [CrossRef]

26. Khan, M.I.; Kim, H.Y.; Miyazaki, S. A review of TiNiPdCu alloy system for high temperature shape memory applications. Shap. Mem. Superelast. 2015, 1, 85-106. [CrossRef]

27. Meng, X.L.; Li, H.; Cai, W.; Hao, S.J.; Cui, L.S. Thermal cycling stability mechanism of Ti50.5Ni33.5Cu11.5Pd4.5 shape memory alloy with near-zero hysteresis. Scr. Mater. 2015, 103, 30-33. [CrossRef]

28. Rehman, S.U.; Khan, M.; Khan, A.N.; Khan, M.I.; Ali, L.; Jaffery, S.H.I. Effect of precipitation hardening and thermomechanical training on microstructure and shape memory properties of Ti50Ni15Pd25Cu10 high temperature shape memory alloys. J. Alloys Compd. 2014, 616, 275-283. [CrossRef]

29. Zhang, Z.J.; James, R.D. Low Hysteresis Materials and Methods. U.S. Patent 20060086432A1, 27 April 2006.

30. Lemke, J.N.; Cadelli, A.; Gallino, F.; Coda, A. Characterization of processing effect on microstructure and hysteresis in NiTiCu alloys. In Proceedings of the ASM International-International Conference on Shape Memory and Superelastic Technologies, SMST 2019, Konstanz, Germany, 13-17 May 2019; pp. 50-51.

31. Giannozzi, P.; Baroni, S.; Bonini, N.; Calandra, M.; Car, R.; Cavazzoni, C.; Ceresoli, D.; Chiarotti, G.L.; Cococcioni, M.; Dabo, I.; et al. QUANTUM ESPRESSO: A modular and open-source software project for quantum simulations of materials. J. Phys. Condens. Matter 2009, 21, 395502. [CrossRef]

32. Lemke, J.N.; Coda, A. DSC and microstructure analysis of high temperature Ni-Ti-Hf, low hysteresis Ni-Ti-Cu and conventional super-elastic and shape memory Ni-Ti alloy ingots and wires. Mater. Today Commun. 2019, 21, 100666. [CrossRef]

33. König, D.; Buenconsejo, P.J.S.; Grochla, D.; Hamann, S.; Pfetzing-Micklich, J.; Ludwig, A. Thickness-dependence of the B2-B19 martensitic transformation in nanoscale shape memory alloy thin films: Zero-hysteresis in $75 \mathrm{~nm}$ thick Ti51Ni38Cu11 thin films. Acta Mater. 2012, 60, 306-313. [CrossRef] 
34. Chowdhury, P.; Sehitoglu, H. Deformation physics of shape memory alloys-Fundamentals at atomistic frontier. Prog. Mater. Sci. 2017, 88, 49-88. [CrossRef]

35. Askeland, R.D.; Phule, P.P. Essentials of Materials Science and Engineering; Thomson: Toronto, ON, Canada, 2004.

36. Gandy, D. Carbon Steel Handbook, Final Report; EPRI-Electric Power Research Institute: Palo Alto, CA, USA, 2007.

37. Lexcellent, C. Shape-Memory Alloys Handbook; John Wiley \& Sons: Hoboken, NJ, USA, 2013.

38. Yin, H.; He, Y.; Moumni, Z.; Sun, Q. Effects of grain size on tensile fatigue life of nanostructured NiTi shape memory alloy. Int. J. Fatigue 2016, 88, 166-177. [CrossRef]

39. Benafan, O.; Bigelow, G.S.; Garg, A.; Noebe, R.D.; Gaydosh, D.J.; Rogers, R.B. Processing and scalability of NiTiHf hightemperature shape memory alloys. Shape Mem. Superelast. 2021, 7, 109-165. [CrossRef]

40. Xi, S.; Su, Y. Phase field study of the microstructural dynamic evolution and mechanical response of NiTi shape memory alloy under mechanical loading. Materials 2021, 14, 183. [CrossRef] [PubMed] 